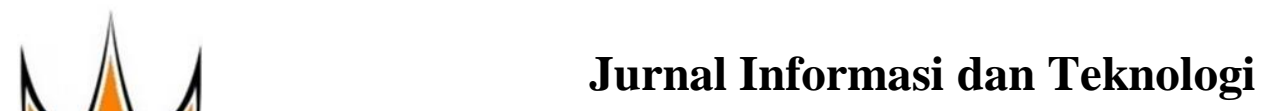

http://www.jidt.org

2021 Vol. 3 No. $1 \quad$ Hal: 1-9 ISSN: 2714-9730 (electronic)

\title{
Prediksi Bed Occupancy Ratio (BOR) Menggunakan Metode Monte Carlo
}

\author{
Dendi Ferdinal ${ }^{1 凶}$, Sarjon Defit ${ }^{2}$, Yuhandri Yunus ${ }^{3}$ \\ ${ }^{1,2,3}$ Universitas Putra Indonesia YPTK Padang \\ dendiferdinal@gmail.com
}

\begin{abstract}
Planning for medical personnel, support staff and hospital facilities for the future is very important in order to carry out excellent and optimal services. Management must be able to predict the percentage of bed use based on a certain period of time or Bed Occupancy Ratio (BOR), in order to see the needs of medical personnel, supporting personnel and hospital facilities. To predict BOR in the future, a Monte Carlo simulation can be carried out using data on the day care for the Second Floor Baby care room in 2017, 2018 and 2019. The Second Floor Baby Room has a bed capacity of 12 units. The prediction rate for the treatment room using the Monte Carlo simulation is $93.09 \%$ for 2018 predictions and $89.78 \%$ for 2019. So this Monte Carlo simulation method simulation can be used in predicting BOR in hospitals. For the 2020 simulation, the BOR is $77.42 \%$ with a total treatment day of 3391 .
\end{abstract}

Keywords: Simulation, Monte Carlo, Bed Occupancy Ratio, Inpatient Room, Hospital.

\begin{abstract}
Abstrak
Perencanaan tenaga medis, tenaga penunjang dan sarana rumah sakit untuk masa yang akan datang sangat penting agar terlaksananya pelayanan prima dan optimal. Manajemen harus dapat memprediksi presentase penggunaan tempat tidur berdasarkan periode waktu tertentu atau Bed Occupancy Ratio (BOR), agar dapat mengetahui kebutuhan tenaga medis, tenaga penunjang dan sarana rumah sakit. Untuk memprediksi BOR pada masa yang akan datang dapat dilakukan simulasi Monte Carlo menggunakan data hari perawatan ruang perawatan Bayi Lantai II tahun 2017, tahun 2018 dan tahun 2019. Ruang Bayi Lantai II memiliki kapasitas tempat tidur sebanyak 12 buah. Tingkat prediksi terhadap ruang perawatan menggunakan simulasi Monte Carlo adalah 93,09\% untuk tahun prediksi 2018 dan 89,78\% untuk tahun 2019. Sehingga metode simulasi Monte Carlo ini dapat digunakan dalam memprediksi BOR di rumah sakit. Untuk simulasi tahun 2020 didapatkan BOR sebesar 77,21\% dengan total hari perawatan sebanyak 3391 hari.
\end{abstract}

Kata kunci: Simulasi, Monte Carlo, Bed Occupancy Ratio, Ruang rawat inap, Rumah Sakit.

(C) $2021 \mathrm{JIdT}$

\section{Pendahuluan}

Pelayanan kesehatan yang bermutu adalah salah satu tolak ukur kepuasan sehingga memiliki efek terhadap keinginan pasien untuk kembali kepada institusi yang memberikan pelayanan kesehatan yang efektif [1]. Pelayanan kesehatan yang efektif sangat erat hubungan dengan ketersedian ruang rawat inap. Bed Occupancy Ratio (BOR) juga sering disebut dengan Bed Occupancy Rate. BOR merupakan persentase pemakaian tempat tidur di unit rawat inap berdasarkan satuan waktu tertentu [2]. BOR juga menjadi alat ukur tingkat efektifitas dan mutu pelayanan di rumah sakit.

Nilai BOR yang tinggi menunjukan tingginya tingkat permintaan atas layanan kesehatan. Namun, nilai BOR yang tinggi belum tentu menunjukan nilai yang ideal. Nilai ideal yang ditetap oleh Kementerian Kesehatan adalah $70 \%-80 \%$. Makin tinggi nilai BOR dapat menyebabkan makin sibuk dan makin beratnya beban kerja petugas di suatu bangsal. Akibatnya, beresiko atas kurangnya perhatian yang dibutuhkan dari petugas terhadap pasien. Namun, semakin rendah BOR berarti semakin sedikit jumlah pemanfaatan tempat tidur yang digunakan untuk merawat pasien dibandingkan dengan jumlah yang telah disediakan. Jumlah pasien yang sedikit dapat menimbulkan berkurangnya pendapatan rumah sakit.

Pemodelan dan simulasi adalah sebuah alat yang menggunakan data masa lalu untuk melakukan uji coba dengan tujuan mendapatkan alternatif terbaik untuk mendukung pengambilan keputusan dalam menyelesaikan suatu permasalahan tertentu [3]. Model merupakan sebuah kondisi atau fenomena alam yang direpresentasikan melalui suatu objek, benda, dan ide yang disederhanakan [4]. Model ini akan dijalankan dengan simulasi komputer, dengan memberi persamaan matematis pada semua varibel yang terdapat pada konsep agar dapat menghasilkan simulasi sesuai perubahan yang direncanakan [5]. Simulasi komputer sejak awal metode Monte Carlo diperkenalkan pada akhir 1940-an oleh Nicholas Metropolis dan S. Ulam, telah diakui bahwa metode statistik yang tepat harus diterapkan pada output simulasi stokastik untuk

Diterima: 14-09-2020 | Revisi: 13-11-2020 | Diterbitkan: 31-03-2021 | DOI: 10.37034/jidt.v3i1.80 
mengevaluasi kinerja sistem atau proses yang sedang dipergunakan sebagai alat untuk menganalisis dan dipelajari [6]. Monte Carlo adalah metode simulasi menyelesaikan masalah yang ada dalam bentuk yang menggunakan angka acak yang diperoleh dari matematika dengan beberapa contoh acak yang statistik Linear Congruential Generator (generator multiplikatif) [17]. Simulasi Monte Carlo merupakan tipe simulasi sebagai perkiraan dalam memperkirakan jumlah probabilistik agar dapat memperoleh penyelesaian pengunjung menggunakan data pengunjung waktu masalah dengan menggunakan metode sampling dari sebelumnya [7].

proses random. Monte Carlo melakukan percobaan pada elemen probabilistic melalui bilangan acak Model adalah gambaran tentang sesuatu yang tidak dengan bantuan pembangkitan bilangan random [18]. dapat diamati secara langsung. Pada umumnya model Bilangan acak yang digunakan merupakan bilangan menjelaskan suatu representasi sistem yang sedang acak berdistribusi normal baku. Simulasi Monte Carlo berjalan saat ini dan menjadi tujuan permasalahan yang memiliki keunggulan yaitu mudah diaplikasikan dan sedang diteliti [8]. Model tersebut tidak hanya hasil mendekati nilai aktual [19].

pengganti dari sistem, tetapi juga merupakan

penyederhanaan dari sistem [9]. Simulasi adalah suatu Untuk mempermudah dalam mengidentifikasikan proses dari model yang digunakan untuk membuat dan hambatan dan masalah dengan menggunakan teknik menguji sebuah sistem nyata dengan menggunakan yang digunakan dalam memprediksi data dengan model matematika [10]. Simulasi biasanya simulasi Monte Carlo yaitu dengan cara dipergunakan untuk menganalisa sebuah sistem saat mempresentasikan masalah kedalam basis Knowledge yang ada dan membantu dalam proses pengambilan Base [20]. Prediksi merupakan proses perkiraan yang keputusan. Simulasi menciptakan suatu nilai yang mungkin terjadi pada masa yang akan datang dengan mungkin terjadi dari estimasi yang diharapkan. Jika adanya informasi terdahulu dan sekarang yang dimiliki, skenario simulasi dilakukan berulang-ulang, akan secara sistematis agar dapat meminimalkan kesalahan. diperoleh nilai yang makin stabil [11]. Dalam referensi Prediksi adalah usaha mencari jawaban sedekat lain juga disebutkan bahwa simulasi merupakan suatu mungkin yang akan terjadi dan tidak harus memberikan alat analisis yang handal untuk merencanakan, jawaban pasti terhadap kejadian yang akan terjadi [21]. mendesain, dan mengontrol proses dari sistem yang kompleks [12].

Metode Monte Carlo digunakan untuk memprediksi BOR pada ruang rawat inap. Metode sangat membantu Metode Monte Carlo merupakan dasar dari algoritma manajemen rumah sakit dalam merencanakan dalam metode simulasi berdasarkan pemikiran kebutuhan tenaga medis, tenaga penunjang dan sarana penyelesaian masalah untuk mendapatkan hasil yang rumah sakit pada masa yang akan datang. Dalam lebih baik dengan cara memberikan nilai acak (random penelitian lainnya simulasi Monte Carlo digunakan number) untuk mendapatkan ketelitian yang lebih untuk optimasi kegiatan pelatihan dengan cara tinggi [13]. Simulasi Monte Carlo adalah metode yang memprediksi jumlah pendaftar pelatihan di Balai sangat praktis yang banyak digunakan dalam Latihan Kerja Dinas Tenaga Kerja dan Transmigrasi memecahkan masalah teknik nyata terutama sistem Provinsi Bengkulu. Penelitian lainnya metode Monte yang dapat diperbaiki. Karena kemampuannya yang Carlo digunakan untuk analisa persediaan oli pada PT. kuat dalam mensimulasikan proses aktual dan perilaku Bintara Andalan Pratama dengan tujuan untuk acak sistem, pendekatan reliabilitas berbasis simulasi menghitung persediaan dengan mengambil 100 sample Monte Carlo dapat menghilangkan ketidakpastian dengan menggunakan random number. Metode Monte dalam pemodelan reliabilitas [14]. Algoritma Monte Carlo juga digunakan untuk memprediksi pajak mineral Carlo akan menentukan pilihan berdasarkan non logam dan batuan agar dapat membantu probabilitas dan densitas yang dimiliki, sehingga akan Pemerintah Kabupaten dalam menentapkan target menentukan pilihan yang terbaik [15]. Karena penerimaan Pajak Mineral Bukan Logam dan Batuan. algoritma ini memerlukan perhitungan dan pengulangan yang sangat kompleks, maka metode ini 2. Metodologi Penelitian umumnya memakai berbagai teknik simulasi komputer dan dilakukan menggunakan komputer. Algoritma Monte Carlo merupakan metode numerik yang digunakan untuk menemukan solusi problem matematis (yang terdiri dari banyak variabel) yang sulit dipecahkan, seperti kalkulus integral atau metode numerik lainnya.

Dikatakan juga metode Monte Carlo adalah algoritma komputasi berdasarkan pengambilan sampel secara Metode penelitian merupakan suatu cara yang dilakukan seseorang untuk mengumpulkan, menyusun serta menganalisis data. Tujuan dari metode tersebut supaya diperoleh makna yang sebenarnya. Metode penelitian merupakan cara ilmiah agar bisa memperoleh dan mengumpulkan data dengan fungsifungsi, tujuan dan kegunaan tertentu. Tahapan yang akan dilakukan dalam penelitian ini dapat dijelaskan dalam kerangka kerja seperti terlihat pada Gambar 1. acak dan berulang untuk menghasilkan nilai numerik. Pada prinsipnya, pendekatan ini dapat digunakan untuk menyelesaikan masalah komputasi yang melibatkan variabel acak [16]. Metode Monte Carlo juga bisa

Jurnal Informasi dan Teknologi Vol. 3 No. 1 (2021) 1-9 


\begin{tabular}{|c|}
\hline Mengidentifikasi Masalah \\
\hline$\nabla$ \\
\hline Menganalisis Masalah \\
\hline$\nabla$ \\
\hline Mengidentifikasi Solusi \\
\hline$\nabla$ \\
\hline Mengumpulkan Data \\
\hline$\nabla$ \\
\hline $\begin{array}{l}\text { Menganalisa Data dengan Metode Monte Carlo } \\
\text { 1. Menentukan Distribusi Probabilitas; } \\
\text { 2. Menentukan Distribusi Probabilitas Kumulatif; } \\
\text { 3. Menentukan Interval Angka Acak; } \\
\text { 4. Membangkitkan Angka Acak; } \\
\text { 5. Simulasi Monte Carlo; } \\
\text { 6. Hasil Simulasi. }\end{array}$ \\
\hline$\nabla$ \\
\hline Merancang Sistem \\
\hline$\nabla$ \\
\hline Implementasi Sistem \\
\hline$\nabla$ \\
\hline Hasil dan Pembahasan \\
\hline
\end{tabular}

Gambar 1. Kerangka Kerja Penelitian

Berdasarkan kerangka kerja penelitian dapat dijelaskan secara umum dalam melakukan simulasi dengan metode Monte Carlo terdapat beberapa langkah yang dapat dilihat berikut:

\subsection{Mengidentifikasi masalah}

Tahapan identifikasi masalah merupakan langkah awal dalam penelitian ini. Tahap ini penting karena peneliti melakukan perumusan masalah dari masalah yang ditemukan pada objek penelitian serta memberikan batasan dari permasalahan yang diteliti agar lebih terarah.

\subsection{Menganalisis masalah}

Tahapan menganalisis masalah adalah untuk kesesuaian antara hasil output dari analisis aplikasi memahami masalah yang dipilih berdasarkan ruang dengan perhitungan manual lingkup dan batasan masalahnya. Tahapan ini diharapkan dapat memberikan solusi yang tepat dalam memprediksi pemanfaatan tempat tidur di masa yang akan datang.

\subsection{Mengidentifikasi solusi}

Guna mencapai suatu target yang diharapkan, maka dipelajari beberapa solusi-solusi yang akan bermanfaat untuk kedepannya. Kemudian solusi-solusi yang

dipelajari tersebut, diseleksi untuk dapat ditentukan solusi-solusi mana yang akan digunakan dalam penelitian. Solusi diambil dari internet, berupa artikel dan jurnal ilmiah tentang Monte Carlo serta bahan bacaan lain yang mendukung penelitian.

\subsection{Mengumpulkan data}

Pada penelitian ini pengumpulan data dilakukan dengan tahap sebagai berikut:

a. Observasi;

b. Wawancara;

c. Studi kepustakaan.

\subsection{Menganalisa data dengan metode Monte Carlo}

Berdasarkan informasi yang didapatkan dari berbagai metode yang dilakukan, serta menentukan kebutuhankebutuhan dari sistem yang digunakan, maka permasalahan tersebut diselesaikan untuk mencapai tujuan dari penelitian ini. Metode yang digunakan didalam penyelesaian masalah adalah dengan metode Monte Carlo. Penyelesaian masalah dilakukan dengan beberapa tahapan:

1. Menentukan distribusi probalitas;

2. Menentukan distribusi probalitas kumulatif;

3. Menentukan interval angka acak;

4. Membangkitkan angka acak;

5. Simulasi Monte Carlo;

6. Hasil simulasi.

\subsection{Merancang sistem}

Tahap merancang sistem dilakukan setelah proses analisa data. Tahap ini dilakukan proses perancangan sistem yang terdiri dari struktur data, program, format masukkan (input), dan format keluaran (output).

\subsection{Implementasi sistem}

Implementasi sistem merupakan tahap uji coba sistem sehingga siap untuk dioperasikan. Tahap ini bertujuan untuk mengkonfirmasi modul-modul perancangan apakah telah berjalan sesuai yang diharapkan. Implementasi metode Monte Carlo ini dilakukan menggunakan bahasa pemrograman PHP dan database MySQL.

\subsection{Hasil dan pembahasan}

Tahap ini dilakukan pengujian untuk membandingkan hasil output dari sistem aplikasi yang dirancang dengan hasil perhitungan manual dengan metode Monte Carlo. Tujuan tahap ini mengetahui apakah diperoleh

\section{Hasil dan Pembahasan}

Sesuai dengan tahapan penerapan metode Monte Carlo untuk simulasi prediksi BOR maka dilakukan dengan proses sesuai metode penelitian, dan didapat hasil sebagai berikut:

Jurnal Informasi dan Teknologi Vol. 3 No. 1 (2021) 1-9 
3.1. Mempersiapkan data tempat tidur dan hari 3.2. Menentukan distribusi probabilitas perawatan ruang rawat inap.

Menentukan distribusi probabilitas data tahun 2017 Pada penelitian ini, data utama yang digunakan adalah berdasarkan data pada Tabel 1 menggunakan rumus data BOR ruang Bayi Lantai II tahun 2017, 2018 dan pada persamaan (1).

2019. Variable yang digunakan dalam penelitian ini adalah hari perawatan per bulannya. Hari perawatan tahun 2017 merupakan data training untuk prediksi tahun 2018, data tahun 2018 merupakan data training untuk prediksi tahun 2019 dan data tahun 2019 digunakan untuk memprediksi hari perawatan tahun 2020 yang akan digunakan untuk menghitung nilai BOR tahun 2020. Data hari perawatan setiap tahunnya dapat dilihat pada Tabel 1, Tabel 2, dan Tabel 3.

Tabel 1. Data Hari Perawatan Ruang Bayi Lantai II (2017)

\begin{tabular}{|c|c|c|c|}
\hline \multicolumn{2}{|c|}{ Jumlah Tempat Tidur: } & \multicolumn{2}{|l|}{12} \\
\hline Bulan & Jumlah Hari & Hari Perawatan & BOR $(\%)$ \\
\hline Januari & 31 & 306 & 82,26 \\
\hline Februari & 28 & 232 & 69,05 \\
\hline Maret & 31 & 253 & 68,01 \\
\hline April & 30 & 237 & 65,01 \\
\hline Mei & 31 & 312 & 65,83 \\
\hline Juni & 30 & 258 & 83,87 \\
\hline Juli & 31 & 173 & 71,67 \\
\hline Agustus & 31 & 325 & 46,51 \\
\hline September & 30 & 273 & 87,37 \\
\hline Oktober & 31 & 360 & 96,77 \\
\hline November & 30 & 252 & 70,00 \\
\hline Desember & 31 & 207 & 55,65 \\
\hline Total & 365 & 3188 & 72,79 \\
\hline
\end{tabular}

Tabel 2. Data Hari Perawatan Ruang Bayi Lantai II (2018)

\begin{tabular}{|c|c|c|c|}
\hline \multicolumn{2}{|c|}{ Jumlah Tempat Tidur : } & \multicolumn{2}{|l|}{12} \\
\hline Bulan & Jumlah Hari & Hari Perawatan & $\operatorname{BOR}(\%)$ \\
\hline Januari & 31 & 270 & 72,58 \\
\hline Februari & 28 & 134 & 39,88 \\
\hline Maret & 31 & 233 & 62,63 \\
\hline April & 30 & 242 & 67,22 \\
\hline Mei & 31 & 317 & 85,22 \\
\hline Juni & 30 & 271 & 75,28 \\
\hline Juli & 31 & 203 & 54,57 \\
\hline Agustus & 31 & 293 & 78,76 \\
\hline September & 30 & 220 & 61,11 \\
\hline Oktober & 31 & 267 & 71,77 \\
\hline November & 30 & 246 & 68,33 \\
\hline Desember & 31 & 281 & 75,54 \\
\hline Total & 365 & 2977 & 67,97 \\
\hline
\end{tabular}

Tabel 3. Data Hari Perawatan Ruang Bayi Lantai II (2019)

\begin{tabular}{|c|c|c|c|}
\hline \multicolumn{2}{|c|}{ Jumlah Tempat Tidur : } & \multicolumn{2}{|l|}{12} \\
\hline Bulan & Jumlah Hari & Hari Perawatan & $\operatorname{BOR}(\%)$ \\
\hline Januari & 31 & 312 & 83,87 \\
\hline Februari & 28 & 222 & 66,07 \\
\hline Maret & 31 & 273 & 73,12 \\
\hline April & 30 & 320 & 88,89 \\
\hline Mei & 31 & 330 & 88,71 \\
\hline Juni & 30 & 274 & 76,11 \\
\hline Juli & 31 & 311 & 83,60 \\
\hline Agustus & 31 & 293 & 78,76 \\
\hline September & 30 & 216 & 60,00 \\
\hline Oktober & 31 & 238 & 63,98 \\
\hline November & 30 & 327 & 90,83 \\
\hline Desember & 31 & 270 & 72,58 \\
\hline Total & 365 & 3385 & 77,28 \\
\hline
\end{tabular}

$$
B_{i}=\frac{R}{S}
$$

Dimana :

$$
\begin{aligned}
& B_{i}=\text { nilai probabilitas per bulan } \\
& R=\text { frekuensi / hari perawatan per bulan } \\
& S=\text { total hari perawatan per tahun }
\end{aligned}
$$

Hasil perhitungan distribusi probabilitas dapat dilihat pada perhitungan diberikut:

$\mathrm{B}_{1}=306 / 3188=0,096$
$\mathrm{~B}_{2}=232 / 3188=0,073$
$\mathrm{~B}_{3}=253 / 3188=0,079$
$\mathrm{~B}_{4}=237 / 3188=0,074$
$\mathrm{~B}_{5}=312 / 3188=0,098$
$\mathrm{~B}_{6}=258 / 3188=0,081$
$\mathrm{~B}_{7}=173 / 3188=0,054$
$\mathrm{~B}_{8}=325 / 3188=0,102$
$\mathrm{~B}_{9}=273 / 3188=0,086$
$\mathrm{~B}_{10}=360 / 3188=0,113$
$\mathrm{~B}_{11}=252 / 3188=0,079$

$\mathrm{B}_{12}=207 / 3188=0,065$

Dari hasil menentukan nilai probabilitas hari perawatan tahun 2017 dimasukan kedalam Tabel 4 untuk memudahkan dalam pembacaan data.

\begin{tabular}{lcc} 
& Tabel 4. Distribusi Probabilitas (2017) \\
\hline \multicolumn{1}{c}{ Bulan } & Hari Perawatan & Distribusi Probabilitas \\
\hline Januari & 306 & 0,096 \\
Februari & 232 & 0,073 \\
Maret & 253 & 0,079 \\
April & 237 & 0,074 \\
Mei & 312 & 0,098 \\
Juni & 258 & 0,081 \\
Juli & 173 & 0,054 \\
Agustus & 325 & 0,102 \\
September & 273 & 0,086 \\
Oktober & 360 & 0,113 \\
\hline
\end{tabular}

Tabel 4. Distribusi Probabilitas (2017) Lanjutan

\begin{tabular}{rcc}
\hline Bulan & Hari Perawatan & Distribusi Probabilitas \\
\hline November & 252 & 0,079 \\
Desember & 207 & 0,065 \\
\hline Total & 3188 & 1,000 \\
\hline
\end{tabular}

Hasil menentukan nilai probabilitas hari perawatan tahun 2018 dapat dilihat pada Tabel 5. 
Dendi Ferdinal, Sarjon Defit, Yuhandri Yunus.

\begin{tabular}{|c|c|c|}
\hline Bulan & Hari Perawatan & Distribusi Probabilitas \\
\hline Januari & 270 & 0,091 \\
\hline Februari & 134 & 0,045 \\
\hline Maret & 233 & 0,078 \\
\hline April & 242 & 0,081 \\
\hline Mei & 317 & 0,106 \\
\hline Juni & 271 & 0,091 \\
\hline Juli & 203 & 0,068 \\
\hline Agustus & 293 & 0,098 \\
\hline September & 220 & 0,074 \\
\hline Oktober & 267 & 0,090 \\
\hline November & 246 & 0,083 \\
\hline Desember & 281 & 0,094 \\
\hline Total & 2977 & 1,000 \\
\hline
\end{tabular}

Hasil perhitungan nilai distribusi probabilitas hari perawatan tahun 2019 dapat dilihat pada Tabel 6.

\begin{tabular}{|c|c|c|}
\hline Bulan & Hari Perawatan & Distribusi Probabilitas \\
\hline Januari & 312 & 0,092 \\
\hline Februari & 222 & 0,066 \\
\hline Maret & 272 & 0,080 \\
\hline April & 320 & 0,095 \\
\hline Mei & 330 & 0,097 \\
\hline Juni & 274 & 0,081 \\
\hline Juli & 311 & 0,092 \\
\hline Agustus & 293 & 0,087 \\
\hline September & 216 & 0,064 \\
\hline Oktober & 238 & 0,070 \\
\hline November & 327 & 0,097 \\
\hline Desember & 270 & 0,080 \\
\hline Total & 3385 & 1,000 \\
\hline
\end{tabular}

3.3. Menentukan distribusi probabilitas kumulatif

$\mathrm{Q}_{1}=\mathrm{B}_{1}=0,096$

$\mathrm{Q}_{2}=\mathrm{B}_{2}+\mathrm{Q}_{1}=0,073+0,096=0,169$

$\mathrm{Q}_{3}=\mathrm{B}_{3}+\mathrm{Q}_{2}=0,079+0,169=0,248$

$\mathrm{Q}_{4}=\mathrm{B}_{4}+\mathrm{Q}_{3}=0,074+0,248=0,322$

$\mathrm{Q}_{5}=\mathrm{B}_{5}+\mathrm{Q}_{4}=0,098+0,322=0,420$

$\mathrm{Q}_{6}=\mathrm{B}_{6}+\mathrm{Q}_{5}=0,081+0,420=0,501$

$\mathrm{Q}_{7}=\mathrm{B}_{7}+\mathrm{Q}_{6}=0,054+0,501=0,556$

$\mathrm{Q}_{8}=\mathrm{B}_{8}+\mathrm{Q}_{7}=0,102+0,556=0,657$

$\mathrm{Q}_{9}=\mathrm{B}_{9}+\mathrm{Q}_{8}=0,086+0,657=0,743$

$\mathrm{Q}_{10}=\mathrm{B}_{10}+\mathrm{Q}_{9}=0,113+0,743=0,856$

$\mathrm{Q}_{11}=\mathrm{B}_{11}+\mathrm{Q}_{10}=0,079+0,856=0,935$

$\mathrm{Q}_{12}=\mathrm{B}_{12}+\mathrm{Q}_{11}=0,065+0,935=1,000$

Dari hasil menentukan nilai probabilitas kumulatif hari perawatan tahun 2017 dimasukan kedalam Tabel 7 untuk memudahkan dalam pembacaan data.

Tabel 7. Distribusi Probabilitas Kumulatif (2017)

\begin{tabular}{lcc}
\hline \multicolumn{1}{c}{ Bulan } & Distribusi Probabilitas & Probabilitas Kumulatif \\
\hline Januari & 0,096 & 0,096 \\
Februari & 0,073 & 0,169 \\
Maret & 0,079 & 0,248 \\
April & 0,074 & 0,322 \\
Mei & 0,098 & 0,420 \\
Juni & 0,081 & 0,501 \\
Juli & 0,054 & 0,556 \\
Agustus & 0,102 & 0,657 \\
September & 0,086 & 0,743 \\
Oktober & 0,113 & 0,856 \\
November & 0,079 & 0,935 \\
Desember & 0,065 & 1,000 \\
\hline \multicolumn{2}{c}{ Total } & 1,000 \\
\hline
\end{tabular}

Menentukan distribusi probabilitas kumulatif untuk hari Hasil menentukan nilai probabilitas kumulatif hari perawatan tahun 2017 dilakukan dengan cara perawatan tahun 2018 dapat dilihat pada Tabel 8. menjumlahkan nilai tiap variable distribusi probabilitas yang ada pada Tabel 4 dengan jumlah nilai probabilitas sebelumnya, kecuali untuk menentukan nilai distribusi probabilitas kumulatif pertama dimana nilainya sama dengan nilai probabilitas itu sendiri. Menentukan distribusi probabilitas kumulatif pertama menggunakan rumus pada persamaan (2).

$$
Q_{1}=B_{1}
$$

Dimana :

$$
\begin{aligned}
& Q_{1}=\text { Nilai probabilitas kumulatif pertama } \\
& B_{1}=\text { Nilai probabilitas pertama }
\end{aligned}
$$

Tabel 8. Distribusi Probabilitas Kumulatif (2018)

\begin{tabular}{lcc}
\hline \multicolumn{1}{c}{ Bulan } & Distribusi Probabilitas & Probabilitas Kumulatif \\
\hline Januari & 0,091 & 0,091 \\
Februari & 0,045 & 0,136 \\
Maret & 0,078 & 0,214 \\
April & 0,081 & 0,295 \\
Mei & 0,106 & 0,402 \\
Juni & 0,091 & 0,493 \\
Juli & 0,068 & 0,561 \\
Agustus & 0,098 & 0,659 \\
September & 0,074 & 0,723 \\
Oktober & 0,090 & 0,823 \\
November & 0,083 & 0,906 \\
Desember & 0,094 & 1,000 \\
\hline \multicolumn{1}{c}{ Total } & 1,000 & \\
\hline \multicolumn{2}{c}{}
\end{tabular}

Untuk menentukan distribusi probabilitas kumulatif selanjutnya menggunakan rumus pada persamaan (3).

Hasil menentukan nilai probabilitas kumulatif hari perawatan tahun 2019 dapat dilihat pada Tabel 9 .

$$
Q_{n}=B_{n}+Q_{n-1}
$$

Dimana :

$Q_{n}=$ Nilai probabilitas kumulatif selanjutnya

$Q_{n-l}=$ Nilai probabilitas kumulatif sebelumnya

$B_{n}=$ Nilai probabilitas selanjutnya

Hasil perhitungan distribusi probabilitas kumulatif dapat dilihat pada perhitungan diberikut:

Jurnal Informasi dan Teknologi Vol. 3 No. 1 (2021) 1-9 
Dendi Ferdinal, Sarjon Defit, Yuhandri Yunus.

\begin{tabular}{|c|c|c|}
\hline Bulan & Distribusi Probabilitas & Probabilitas Kumulatif \\
\hline Januari & 0,092 & 0,092 \\
\hline Februari & 0,066 & 0,158 \\
\hline Maret & 0,080 & 0,238 \\
\hline April & 0,095 & 0,333 \\
\hline Mei & 0,097 & 0,430 \\
\hline Juni & 0,081 & 0,511 \\
\hline Juli & 0,092 & 0,603 \\
\hline Agustus & 0,087 & 0,690 \\
\hline September & 0,064 & 0,753 \\
\hline Oktober & 0,070 & 0,824 \\
\hline November & 0,097 & 0,920 \\
\hline Desember & 0,080 & 1,000 \\
\hline Total & 1,000 & \\
\hline
\end{tabular}

\subsection{Menentukan interval angka acak}

Nilai interval angka acak diperoleh dari nilai angka probabilitas kumulatif pada tahapan sebelumnya. Adapun fungsi dari nilai angka acak adalah pembatas dari nilai antara variable satu dengan variable lainnya yang berfungsi sebagai nilai acuan hasil simulasi. Pada nilai angka acak sendiri terdiri dari 2 bagian yaitu nilai angka acak batas awal dan nilai angka acak batas akhir. Adapun untuk menentukan nilai batasan pada variable angka acak adalah :

a. Nilai batas awal untuk variable pertama dimulai dengan nilai 0 .

b. Nilai batas akhir ditentukan dengan cara mengalikan nilai probabilitas kumulatif masingmasing variable dengan angka 100 dan dibulatkan kemudian dikurangi dengan angka 1.

c. Nilai batas awal untuk variable kedua dan seterusnya diperoleh dari nilai batas akhir variable sebelumnya.

Hasil penentuan nilai interval angka acak tahun 2017 dapat dilihat pada Tabel 10.

Tabel 10. Interval Angka Acak (2017)

\begin{tabular}{lccc}
\hline \multirow{2}{*}{ Bulan } & Probabilitas Kumulatif & \multicolumn{2}{c}{ Interval Angka Acak } \\
\cline { 3 - 4 } & & Awal & Akhir \\
\hline Januari & 0,096 & 0 & 9 \\
Februari & 0,169 & 10 & 16 \\
Maret & 0,248 & 17 & 24 \\
April & 0,322 & 25 & 31 \\
Mei & 0,420 & 32 & 41 \\
Juni & 0,501 & 42 & 49 \\
Juli & 0,556 & 50 & 55 \\
Agustus & 0,657 & 56 & 65 \\
September & 0,743 & 66 & 73 \\
Oktober & 0,856 & 74 & 85 \\
November & 0,935 & 86 & 93 \\
Desember & 1,000 & 94 & 99 \\
\hline
\end{tabular}

Hasil penentuan nilai interval angka acak tahun 2018 dapat dilihat pada Tabel 11.

Tabel 11. Interval Angka Acak (2018)

\begin{tabular}{lccc}
\hline \multirow{2}{*}{ Bulan } & Probabilitas Kumulatif & \multicolumn{2}{c}{ Interval Angka Acak } \\
\cline { 3 - 4 } & & Awal & Akhir \\
\hline Januari & 0,091 & 0 & 8 \\
Februari & 0,136 & 9 & 13 \\
Maret & 0,214 & 14 & 20 \\
April & 0,295 & 21 & 29 \\
\hline
\end{tabular}

Tabel 11. Interval Angka Acak (2018) Lanjutan

\begin{tabular}{lccc}
\hline \multirow{2}{*}{ Bulan } & Probabilitas Kumulatif & \multicolumn{2}{c}{ Interval Angka Acak } \\
\cline { 3 - 4 } & & Awal & Akhir \\
\hline Mei & 0,402 & 30 & 39 \\
Juni & 0,493 & 40 & 48 \\
Juli & 0,561 & 49 & 55 \\
Agustus & 0,659 & 56 & 65 \\
September & 0,723 & 66 & 72 \\
Oktober & 0,823 & 73 & 81 \\
November & 0,906 & 82 & 90 \\
Desember & 1,000 & 91 & 99 \\
\hline
\end{tabular}

Hasil penentuan nilai interval angka acak tahun 2019 dapat dilihat pada Tabel 12 .

\begin{tabular}{lccc} 
& \multicolumn{3}{c}{ Tabel 12. Interval Angka Acak (2019) } \\
\hline \multirow{2}{*}{ Bulan } & Probabilitas Kumulatif & \multicolumn{2}{c}{ Interval Angka Acak } \\
\cline { 3 - 4 } & & Awal & Akhir \\
\hline Januari & 0,092 & 0 & 8 \\
Februari & 0,158 & 9 & 15 \\
Maret & 0,238 & 16 & 23 \\
April & 0,333 & 24 & 32 \\
Mei & 0,430 & 33 & 42 \\
Juni & 0,511 & 43 & 50 \\
Juli & 0,603 & 51 & 59 \\
Agustus & 0,690 & 60 & 68 \\
September & 0,753 & 69 & 74 \\
Oktober & 0,824 & 75 & 81 \\
November & 0,920 & 82 & 91 \\
Desember & 1,000 & 92 & 99 \\
\hline
\end{tabular}

\subsection{Membangkitkan angka acak}

Sebelum membangkitkan angka acak harus dipastikan nilai interval angka acak yang dibentuk sudah tersedia. Terdapat 2 metode yang biasa digunakan untuk membangkitkan angka acak yaitu Mixed Congruent Method dan Multiplicative Method. Pada penelitian ini untuk membangkitkan angka acak menggunakan Mixed Congruent Method. Metode ini memerlukan 4 parameter yang nilainya harus ditetapkan terlebih dahulu yaitu $\mathrm{d}$, e, $\mathrm{h}$ dan $\mathrm{W}_{0}$. 4 parameter tersebut berbentuk bilangan bulat. Untuk membangkitkan angka acak menggunakan rumus pada persamaan (4).

$$
W_{i}=\left(d . W_{\mathrm{i}-1}+e\right) \bmod h
$$

Dimana :

$$
\begin{aligned}
W_{i}= & \text { Nilai angka acak ke-i } \\
d= & \text { Konstansta Penggali }(\mathrm{d}<\mathrm{h}) \\
e= & \text { Konstanta Pergeseran }(\mathrm{e}<\mathrm{h}) \\
h= & \text { Konstanta Modulus }(\mathrm{h}>0) \\
W_{i-l}= & \text { Nilai angka acak sebelumnya }\left(\text { Untuk } \mathrm{W}_{0}\right. \\
& \text { merupakan bilangan awal yang merupakan }
\end{aligned}
$$


kunci pembangkit dan disebut juga umpan

(seed), nilai $\mathrm{W}_{0}$ merupakan bilangan bulat

dengan ketentuan $\mathrm{W}_{0} \geq 0$ dan $\mathrm{W}_{0}<\mathrm{h}$ )

Untuk membangkitkan angka acak, parameterparameter yang akan digunakan yaitu nilai $d=39, e=95$, $\mathrm{h}=97, \mathrm{~W}_{0}=27$. Proses perhitungan membangkitkan angka acak adalah sebagai berikut:

$\mathrm{W}_{\mathrm{i}}=\left(\mathrm{d} \cdot \mathrm{W}_{\mathrm{i}-1}+\mathrm{e}\right) \bmod \mathrm{h}$

$\mathrm{W}_{1}=(39 \times 27+95) \bmod 97=81$

$\mathrm{W}_{2}=(39 \times 81+95) \bmod 97=53$

$\mathrm{W}_{3}=(39 \times 53+95) \bmod 97=28$

$\mathrm{W}_{4}=(39 \times 28+95) \bmod 97=23$

$\mathrm{W}_{5}=(39 \times 23+95) \bmod 97=22$

$\mathrm{W}_{6}=(39 \times 22+95) \bmod 97=80$

$\mathrm{W}_{7}=(39 \times 80+95) \bmod 97=14$

$\mathrm{W}_{8}=(39 \times 14+95) \bmod 97=59$

$\mathrm{W}_{9}=(39 \times 59+95) \bmod 97=68$

$\mathrm{W}_{10}=(39 \times 68+95) \bmod 97=31$

$\mathrm{W}_{11}=(39 \times 31+95) \bmod 97=43$

$\mathrm{W}_{12}=(39 \times 43+95) \bmod 97=26$

Hasil membangkitkan angka acak dapat dilihat pada Tabel 13.

Tabel 13. Angka Acak

\begin{tabular}{cc}
\hline No & Angka Acak \\
\hline 1 & 81 \\
2 & 53 \\
3 & 28 \\
4 & 23 \\
5 & 22 \\
6 & 80 \\
7 & 14 \\
8 & 59 \\
9 & 68 \\
10 & 31 \\
11 & 43 \\
12 & 26 \\
\hline
\end{tabular}

\subsection{Simulasi Monte Carlo}

Simulasi dilakukan dengan cara membandingkan nilai angka acak dengan nilai interval angka acak pada Tabel 10, Tabel 11 dan Tabel 12. Nilai dari hasil simulasi diambil dari hari perawatan data training berdasarkan angka acak yang dibangkitkan dan dibandingkan dengan nilai interval angka acak data training tersebut.

\subsection{Hasil Simulasi}

Hasil simulasi untuk tahun 2018 dapat dilihat pada Tabel 14.
Tabel 14. Hasil Simulasi Prediksi Untuk Tahun 2018

\begin{tabular}{lccc}
\hline \multirow{2}{*}{ Bulan } & \multicolumn{2}{c}{ Hari Perawatan (Hari) } & $\begin{array}{c}\text { Tingkat } \\
\text { Akurasi (\%) }\end{array}$ \\
\cline { 2 - 3 } & Data Real & Hasil Simulasi & \\
\hline Januari & 270 & 360 & 75,00 \\
Februari & 134 & 173 & 77,46 \\
Maret & 233 & 237 & 98,31 \\
April & 242 & 253 & 95,65 \\
Mei & 317 & 253 & 79,81 \\
Juni & 271 & 360 & 75,28 \\
Juli & 203 & 232 & 87,50 \\
Agustus & 293 & 325 & 90,15 \\
September & 220 & 273 & 80,59 \\
Oktober & 267 & 237 & 88,76 \\
\hline
\end{tabular}

Tabel 14. Hasil Simulasi Prediksi Untuk Tahun 2018 Lanjutan

\begin{tabular}{lccc}
\hline \multirow{2}{*}{ Bulan } & \multicolumn{2}{c}{ Hari Perawatan (Hari) } & $\begin{array}{c}\text { Tingkat } \\
\text { Akurasi (\%) }\end{array}$ \\
\cline { 2 - 3 } & Data Real & Hasil Simulasi & \\
\hline Maret & 233 & 237 & 98,31 \\
April & 242 & 253 & 95,65 \\
Mei & 317 & 253 & 79,81 \\
Juni & 271 & 360 & 75,28 \\
Juli & 203 & 232 & 87,50 \\
Agustus & 293 & 325 & 90,15 \\
September & 220 & 273 & 80,59 \\
Oktober & 267 & 237 & 88,76 \\
November & 246 & 258 & 95,35 \\
Desember & 281 & 237 & 84,34 \\
\hline Jumlah & 2977 & 3198 & 93,09 \\
\hline
\end{tabular}

Hasil simulasi untuk tahun 2019 dapat dilihat pada Tabel 15 .

Tabel 15. Hasil Simulasi Prediksi Untuk Tahun 2019

\begin{tabular}{lccc}
\hline \multirow{2}{*}{ Bulan } & \multicolumn{2}{c}{ Hari Perawatan (Hari) } & $\begin{array}{c}\text { Tingkat } \\
\text { Akurasi }(\%)\end{array}$ \\
\cline { 2 - 3 } & Data Real & Hasil Simulasi & 85,58 \\
Januari & 312 & 267 & 91,44 \\
Februari & 222 & 203 & 88,97 \\
Maret & 272 & 242 & 75,63 \\
April & 320 & 242 & 73,33 \\
Mei & 330 & 242 & 97,45 \\
Juni & 274 & 267 & 74,92 \\
Juli & 311 & 233 & 100,00 \\
Agustus & 293 & 293 & 98,18 \\
September & 216 & 220 & 75,08 \\
Oktober & 238 & 317 & 82,87 \\
November & 327 & 271 & 89,63 \\
Desember & 270 & 242 & 89,78 \\
\hline Jumlah & 3385 & 3039 & \\
\hline
\end{tabular}

Untuk menghitung nilai BOR menggunakan rumus pada persamaan (5).

$$
B O R_{n}=\frac{S_{n}}{T \quad x \quad M_{n}}
$$

Dimana :

$$
\begin{array}{ll}
B O R_{n} & =\text { BOR per bulan } ; \\
S_{n} & =\text { hasil simulasi hari perawatan per bulan } \\
T & =\text { jumlah tempat tidur } \\
M_{n} & =\text { jumlah hari per bulan. }
\end{array}
$$


Hasil simulasi tahun 2020 dapat diketahui nilai BOR Daftar Rujukan seperti perhitungan berikut:

$$
\begin{aligned}
& \mathrm{BOR}_{\mathrm{n}}=\mathrm{S}_{\mathrm{n}} /\left(\mathrm{T} \times \mathrm{M}_{\mathrm{n}}\right) \\
& \mathrm{BOR}_{1}=238 /(12 \times 31)=0,6398=63,98 \% \\
& \mathrm{BOR}_{2}=311 /(12 \times 29)=0,8937=89,37 \% \\
& \mathrm{BOR}_{3}=320 /(12 \times 31)=0,8602=86,02 \% \\
& \mathrm{BOR}_{4}=272 /(12 \times 30)=0,7556=75,56 \% \\
& \mathrm{BOR}_{5}=272 /(12 \times 31)=0,7312=73,12 \% \\
& \mathrm{BOR}_{6}=238 /(12 \times 30)=0,6611=66,11 \% \\
& \mathrm{BOR}_{7}=222 /(12 \times 31)=0,5968=59,68 \% \\
& \mathrm{BOR}_{8}=311 /(12 \times 31)=0,8360=83,60 \% \\
& \mathrm{BOR}_{9}=293 /(12 \times 30)=0,8139=81,39 \% \\
& \mathrm{BOR}_{10}=320 /(12 \times 31)=0,8602=86,02 \% \\
& \mathrm{BOR}_{11}=274 /(12 \times 30)=0,7611=76,11 \% \\
& \mathrm{BOR}_{12}=320 /(12 \times 31)=0,8602=86,02 \%
\end{aligned}
$$

Hasil simulasi untuk tahun 2020 dapat dilihat pada Tabel 16 untuk memudahkan dalam pembacaan data.

Tabel 16. Hasil Simulasi Prediksi Untuk Tahun 2020

\begin{tabular}{lccc}
\hline \multicolumn{1}{c}{ Jumlah Tempat Tidur : 12} & & $\begin{array}{c}\text { BOR } \\
(\%)\end{array}$ \\
\cline { 1 - 3 } \multicolumn{1}{c}{ Bulan } & Jumlah Hari & Hasil Simulasi & 63,98 \\
Januari & 31 & 238 & 89,37 \\
Februari & 29 & 311 & 86,02 \\
Maret & 31 & 320 & 75,56 \\
April & 30 & 272 & 73,12 \\
Mei & 31 & 272 & 66,11 \\
Juni & 30 & 238 & 59,68 \\
Juli & 31 & 222 & 83,60 \\
Agustus & 31 & 311 & 81,39 \\
September & 30 & 293 & 86,02 \\
Oktober & 31 & 320 & 76,11 \\
November & 30 & 274 & 86,02 \\
Desember & 31 & 320 & 77,21 \\
\hline Jumlah & 366 & 3391 & \\
\hline
\end{tabular}

Simulasi untuk tahun 2018 dan 2019 merupakan simulasi percobaan menggunakan data tahun sebelumnya. Hasil simulasi tahun 2018 menggunakan data training tahun 2017 memiliki tingkat akurasi sebesar 93,09\% seperti terlihat pada Tabel 14. Untuk hasil simulasi tahun 2019 menggunakan data training tahun 2018 memiliki tingkat akurasi sebesar 89,78\% yang disajikan pada Tabel 15. Hasil simulasi hari perawatan tahun 2020 menggunakan data tahun 2019 adalah 3391 hari, dengan nilai BOR sebesar 77,21\% seperti terlihat pada Tabel 16.

\section{Kesimpulan}

Dengan menggunakan simulasi Monte Carlo yang memanfaatkan data-data hari perawatan sebelumnya maka prediksi BOR dapat ditentukan untuk tahun berikutnya dan dapat diprediksi hasilnya. Dari dua tahun pengujian yang dilakukan maka didapat prediksi terhadap ruang perawatan menggunakan simulasi Monte Carlo adalah 93,09\% untuk tahun prediksi 2018 dan 89,78\% untuk tahun 2019. Sehingga metode simulasi Monte Carlo ini dapat digunakan dalam memprediksi BOR di rumah sakit. Untuk simulasi tahun 2020 didapatkan BOR per tahun sebesar 77,21\% dengan total hari perawatan sebanyak 3391 hari.
[1] Meidina, C. I. (2018). Analisa Hubungan Kepuasan Pelayanan Kesehatan dengan Pencapaian Bed Occupancy Rate (BOR) di Rumah Sakit Bhayangkara Tk-II Medan. Jurnal Ilmiah Simantek, 2(2)

[2] Geni, B. Y., Santony, J., \& Sumijan. (2019). Prediksi Pendapatan Terbesar pada Penjualan Produk Cat dengan Menggunakan Metode Monte Carlo. Jurnal Informatika Ekonomi Bisnis, 1(4), 15-20. DOI: https://doi.org/10.37034/infeb.v1i4.5

[3] Nurdian, R. A., Prasidyajyandalu, R., Masyhuri, M. B. A., \& Rolliawati, D. (2020). Pemodelan Simulasi Produksi Bakso dan Sistem Distribusi. Jurnal Technopreneur (JTech), 8(1), 59-64. DOI: https://doi.org/10.30869/jtech.v8i1.413

[4] Romadhon, A., \& Suryani, E. (2020). Pemodelan Simulasi Sistem Dinamik untuk Meningkatkan Jumlah Pendapatan Unit Rawat Inap Rumah Sakit Islam Surabaya A. Yani. Jurnal Teknologi Informasi dan Ilmu Komputer, 7(3), 581-590. DOI: http://dx.doi.org/10.25126/jtiik.2020703126 .

[5] Alexopoulos, C., \& Kelton, W. D. (2017). A Concise History of Simulation Output Analysis. Winter Simulation Conference.

[6] Irfani, M. H., \& Dafid, D. (2017). Estimasi Pengunjung Menggunakan Simulasi Monte Carlo Pada Warung Internet XYZ. Jurnal Ilmiah Informatika Global, 8(2).

[7] Mahessya, R. A., Mardianti, L., \& Sovia, R. (2017). Pemodelan dan Simulasi Sistem Antrian Pelayanan Pelanggan Menggunakan Metode Monte Carlo Pada PT Pos Indonesia (Persero) Padang. Jurnal Ilmu Komputer, 6(1), 15-24. DOI: https://doi.org/10.33060/JIK/2017/Vol6.Iss1.41 .

[8] Hutahaean, H. D. (2018). Analisa Simulasi Monte Carlo Untuk Memprediksi Tingkat Kehadiran mahasiswa dalam Perkuliahan (Studi Kasus: STMIK Pelita Nusantara). Journal of Informatic Pelita Nusantara,3(1).

[9] Rahayu, T. K. (2019). Simulasi Monte Carlo Untuk Memprediksi Keuntungan Penjualan. Musamus Journal of Research Information and Communication Technology, 2(1), 1-6.

[10] Trisna, N., Safitri, W., \& Pratiwi, M. (2019). Penerapan Sistem Antrian Sebagai Upaya Pengoptimalkan Pelayanan Terhadap Pasien Pada Loket Pengambilan Obat Di RSI. Ibnu Sina Pasaman Barat dengan Menggunakan Metode Monte Carlo. JurTI (Jurnal Teknologi Informasi), 3(1), 7-15. DOI: https://doi.org/10.36294/jurti.v3i1.681

[11] Setyawan, E. B., Novitasari, N., \& Muttaqin, P. S. (2020). Prediksi Volatilitas Harga Jual Produk Pada E-Commerce untuk Independent Stockashtic Data Menggunakan Simulasi Monte Carlo. KAIZEN: Management Systems \& Industrial Engineering Journal, 3(1), 42-49. DOI: http://doi.org/10.25273/kaizen.v3i1.6253 .

[12] Irwanto, M. R., Widiyaningtyas, T., \& Arifin, M. Z. (2017). Implementasi Algoritma Monte Carlo Pada Sistem Informasi Penerimaan Peserta Didik Baru (PPDB) Secara Online. Teknologi dan Kejuruan: Jurnal teknologi, Kejuruan dan Pengajarannya, 40(1), 69-78.

[13] Syahrin, E., Santony, J., \& Na'am, J. (2018). Pemodelan Penjualan Produk Herbal Menggunakan Metode Monte Carlo. Jurnal KomtekInfo, 5(3), 33-41. DOI: https://doi.org/10.35134/komtekinfo.v5i3.148 .

[14] Astia, R. Y., Santony, J., \& Sumijan, S. (2019). Prediction of Amount of Use of Planning Family Contraception Equipment Using Monte Carlo Method (Case Study In Linggo Sari Baganti District). Indonesian Journal of Artificial Intelligence and Data $\begin{array}{lll}\text { Mining, } & 2(1), & 28-36 .\end{array}$ http://dx.doi.org/10.24014/ijaidm.v2i1.5825 .

[15]Junadhi., Agustin., \& Susanti. (2017). Perbandingan Metode Backpropagation dengan Metode Monte Carlo dalam memprediksi jumlah penderita demam Berdarah Dengue di Kota Pekanbaru. Rabit: Jurnal Teknologi dan Sistem Informasi

Jurnal Informasi dan Teknologi Vol. 3 No. 1 (2021) 1-9 
Dendi Ferdinal, Sarjon Defit, Yuhandri Yunus.

Univrab, 2(2), 72-82.

https://doi.org/10.36341/rabit.v2i2.185 .

[16]Pamungkas, I., Irawan, H. T., Arhami, A., \& Dirhamsyah, M. (2018). Simulasi Monte Carlo Untuk Menentukan Keandalan Pada Bagian Boiler di Pembangkit Listrik Berbasis Batubara. Jurnal Optimalisasi, 4(2), 83-96.

[17] Yusmaity., Santony, J., \& Yunus, Y. (2019). Simulasi Monte Carlo untuk Memprediksi Hasil Ujian Nasional (Studi Kasus di SMKN 2 Pekanbaru). Jurnal Informasi dan Teknologi, 1(4), 1-6. DOI: https://doi.org/10.37034/jidt.v1i4.21

[18]Rohmawati, F., Rohman, M. G., \& Mujilahwati, S. (2017). Sistem Prediksi Jumlah Pengunjung Wisata Wego Kec. Sugio Kab. Lamongan Menggunakan Metode Fuzzy Time Series. Joutica, 2(2). DOI: https://doi.org/10.30736/jti.v2i2.66 .
DOI: [19]Zulfiandry, R. (2018). Optimasi Kegiatan Pelatihan Menggunakan Metode Simulasi Monte Carlo (Studi Kasus di Balai Latihan Kerja Dinas Tenaga Kerja dan Transmigrasi Provinsi Bengkulu). ILKOM Jurnal Ilmiah, 10(1), 113-119. DOI: https://doi.org/10.33096/ilkom.v10i1.252.113-119.

[20]Raja V. N. L, \& Adam R. (2019). Analisa Persediaan Oli Pada PT Bintara Andalan Pratama dengan Metode Simulasi Monte Carlo. Prosiding Semnastek, 1(1).

[21]Santony, J. (2019). Prediksi Pajak Mineral Non Logam dan Batuan dengan Metode Monte Carlo. Jurnal Informasi dan Teknologi, $1(4)$ 32-37. DOI: 